\title{
FOTOJORNALISMO E SOFTWARE LIVRE: FOTOLIVRE.UFSC
}

Originais recebidos em: 15/03/2010

Aceito para publicação em: 13/08/2011

Jessé Antunes Torres

Universidade Federal de Santa Catarina

jessehtorres@gmail.com

Raquel Ritter Longhi

Universidade Federal de Santa Catarina

raqlonghi@gmail.com

\section{Resumo}

Relato da experiência de extensão desenvolvida no Projeto Fotolivre.ufsc ${ }^{l}$, site elaborado com softwares livres e utilizando a licença Creative Commons. O objetivo principal do projeto foi divulgar a produção discente das disciplinas de Fotografia do Curso de Jornalismo da UFSC, na forma de banco de imagens. A metodologia desenvolvida primeiramente com a pesquisa bibliográfica sobre banco de imagens e ferramentas livres para a criação de produtos fotojornalísticos online e sua utilização. Em seguida, foi criado o site Fotolivre.ufsc, feito com aplicativos livres, como o Joomla, com a estruturação de um banco de imagens da produção fotográfica dos alunos. O site Fotolivre.ufsc foi lançado durante a $8^{\mathrm{a}}$ Sepex - Semana de Ensino, Pesquisa e Extensão da UFSC, em outubro de 2009. Realizado no período de maio a dezembro, o projeto constituiu-se em uma iniciativa de interesse para a comunidade em geral, estimulando a produção fotojornalística acadêmica e o uso de softwares livres.
Palavras-chave: Banco de Imagens. Software livre - Joomla. Fotolivre.ufsc.

\section{PHOTOJOURNALISM AND FREE SOFTWARE: FOTOLIVRE.UFSC}

\begin{abstract}
Report on the experience of extension developed in the Project Fotolivre.ufsc, site made with free software and using the Creative Commons license. The main goal was to promote the student's production of Photojournalism disciplines in the Course of Journalism at UFSC, in the form of stock photography images. The methodology was first developed with the literature on stock images and free tools for creating online photojournalistic products and its use. Then the site was created, made with free applications such as Joomla, with the structuring of a database of photographic images made by the students. The site was launched during the 8th Sepex - Week of Teaching, Research and Extension of UFSC, in October 2009. Conducted from $01 / 05$ to $31 / 12 / 2009$, the project consisted in an initiative of interest to the community in general, stimulating the academic photojournalistic production and the use of free software.
\end{abstract}

Keywords: Image Database. Free software - Joomla. Fotolivre.ufsc.

\footnotetext{
${ }^{1} \mathrm{http}: / / \mathrm{www}$. fotolivre.ufsc.br/
} 


\section{CONSIDERAÇÕES INICIAIS}

Estimular a produção em fotojornalismo, integrando o ensino com a extensão universitária, através da divulgação da produção dos alunos num banco de imagens on-line. Essa foi a proposta de criação do projeto Fotolivre.ufsc, que objetivou criar um banco de imagens produzidas nas disciplinas de Fotografia, especificamente na matéria de Fotojornalismo, do Curso de Jornalismo da Universidade Federal de Santa Catarina (UFSC). Foi utilizado apenas software livre, e o material foi disponibilizado sob licença Creative Commons. Lançado em outubro de 2009, durante a Sepex - Semana de Pesquisa e Extensão da UFSC, o projeto logo chamou a atenção do público na World Wide Web e na feira universitária, exatamente por apresentar uma proposta de utilização de ferramentas livres e colaboração, na forma de uso das imagens com citação de autores e sem fins lucrativos, como prevê a licença Creative Commons.

O universo das Novas Tecnologias de Informação e Comunicação (NTCI) proporciona não apenas espaços para armazenamento e disponibilização da informação em diversos formatos, como também aplicativos para a criação e divulgação, tais como sites e estruturas de bancos de dados. Como observou Alvarez Marcos (2003, p. 239), pela natureza digital do ciberespaço e aceleração tecnológica, resultará em novos meios, flexíveis e adaptáveis a mudanças sucessivas.

O fotojornalismo, na Web, ganha outra dimensão, segundo Canavilhas (2007), pela possibilidade de maior espaço, o que permite formatos como galeria de imagens, slide-shows, entre outros. O webjornalismo utiliza em grande escala slide-shows, produtos informativos com imagens pioneiros desse suporte, de acordo com McAdams (2005). A hipermídia, linguagem específica da plataforma Web que permite a integração de texto, imagem e som, foi desenvolvendo-se com o avanço de softwares e hardwares e, assim, outros tipos de objetos noticiosos foram surgindo, entre os quais, os chamados "especiais multimídia", que conjugam a grande reportagem do impresso à linguagem hipermídia da Web. Slide-shows, galerias de imagens, especiais multimídia são alguns dos produtos jornalísticos que buscam a imagem como sua grande força. 
Da mesma forma que a imagem tem um protagonismo na linguagem dos novos meios, especialmente no webjornalismo, a função do leitor é remodelada; ele agora é um usuário, um utilizador com uma bagagem cultural de conhecimento e fruição de meios como o cinema, a televisão e o impresso, entre outros (MANOVICH, 2006). Isso tem função decisiva na configuração das linguagens nos meios digitais, manipuláveis tanto no sentido da produção da informação, como da fruição ou utilização.

Em momentos, ambas ocorrem conjuntamente, como se verifica na atual configuração dos meios digitais e conectados, onde é permitido ao usuário ser, ao mesmo tempo, um utilizador e um produtor de informação, ao poder utilizar ferramentas de criação de formatos que vão do blog ao slide-show. Em muitos desses casos, podem ser utilizados softwares livres, programas de computador que não implicam a compra de licenças de uso, mas atuam através da troca de experiências por usuários conectados à Internet. Nesse sentido, um dos objetivos do projeto é o estímulo à criação de produtos hipermidiáticos fotojornalísticos utilizando software livre, já que, no atual cenário da formação jornalística, a demanda por conhecimentos relativos a ferramentas de criação para os meios digitais é muito grande.

A ideia de criar um site com banco de imagens produzidas pelos alunos do Curso de Jornalismo da UFSC nasceu dentro desse cenário, como uma forma de abrir um espaço para divulgação de sua produção e propiciar a criação e experimentação de formatos fotojornalísticos nos meios digitais, dentro de uma estrutura que possa disponibilizar essa produção como um banco de imagens virtual. Dessa forma, o projeto Fotolivre.ufsc é um banco de imagens produzidas no Curso de Jornalismo da UFSC. Todo o trabalho é feito com o uso de softwares e ferramentas livres, criando um ambiente de colaboração e divulgação de material que não infringe leis de direito autoral. O Fotolivre.ufsc é um Projeto de Extensão contemplado com o Pró-Bolsa e o Pro-Extensão 2009, ligado também ao Núcleo de Estudos e Produção Hipermídia Aplicados ao Jornalismo, Nephi-Jor.

O Fotolivre.ufsc envolveu os alunos em várias etapas do fazer fotojornalístico, desde a experimentação com ferramentas de autoria e compartilhamento de sua produção, até a divulgação de seu trabalho, além de servir para a comunidade em geral como um banco de imagens.

O projeto traz em si uma discussão muito pertinente nos tempos atuais: rever os dispositivos legais que tratam dos direitos autorais, pois estes encontram-se defasados. Através de leis mais flexíveis, como as licenças Creative Commons, certos usos do material 
são permitidos, embora o autor não abra mão dos seus direitos. Todos os anos, no curso de Jornalismo, são produzidas imagens que não são utilizadas e que poderiam ser aproveitadas. Por outro lado, muitas vezes, ao produzir um projeto, usam-se imagens disponíveis na Web sem a devida permissão.

O objetivo geral deste estudo foi criar um banco de imagens produzidas pelos alunos do Curso de Jornalismo da UFSC. Os objetivos específicos estiveram contemplados em:

- Envolver os alunos em várias etapas do fazer fotojornalístico, proporcionando a experimentação com ferramentas de autoria de formatos fotojornalśiticos e disponibilização para compartilhamento de sua produção.

- Estimular a utilização de softwares livres na criação do site.

- Disponibilizar as imagens à comunidade acadêmica e à comunidade em geral, através do acesso à Internet.

\section{MATERIAL E MÉTODOS}

A primeira etapa constou de pesquisa bibliográfica e on-line sobre banco de dados e de imagens, ferramentas livres para criação de produtos fotojornalísticos on-line e utilização desses aplicativos, e foi feita por colaboradores bolsistas, nos meses de maio a julho. Também foi solicitado parecer ao Departamento de Direito Autoral da UFSC e o modelo de contrato de autorização da publicação das imagens no site, sob licença Creative Commons, trabalho realizado pela equipe junto com a coordenação da pesquisa.

Numa segunda etapa, de agosto a outubro, foram criadas contas de e-mail e espaço na rede social Twitter, e elaborou-se o site propriamente dito. A equipe realizou, ainda, experimentações com ferramentas de produção de slide-shows fotojornalísticos e sua consequente disponibilização através do site, feitas pelos bolsistas. Em outubro foi feito o lançamento do site, durante a $8^{\mathrm{a}}$ SEPEX - Semana de Ensino, Pesquisa e Extensão da UFSC, para o público em geral. Foram disponibilizadas no site, nesse primeiro momento, 24 fotos, provenientes da disciplina de Fotojornalismo I do Curso de Jornalismo, num trabalho feito pelos bolsistas, que também realizaram, junto à coordenadora, a busca das assinaturas dos alunos nos contratos de cedência de uso das imagens no site. Em um segundo momento, a preparação para o lançamento contou com a criação de um impresso, na forma de marcador 
de páginas e um banner, com o apoio do DAE - Departamento de Administração Escolar, na pessoa de seu diretor, Dalton Barreto. Em novembro, o projeto foi apresentado ao XXVII Seminário de Extensão Universitária da Região Sul - SEURS, na cidade de Santa Maria (LIMA, 2009).

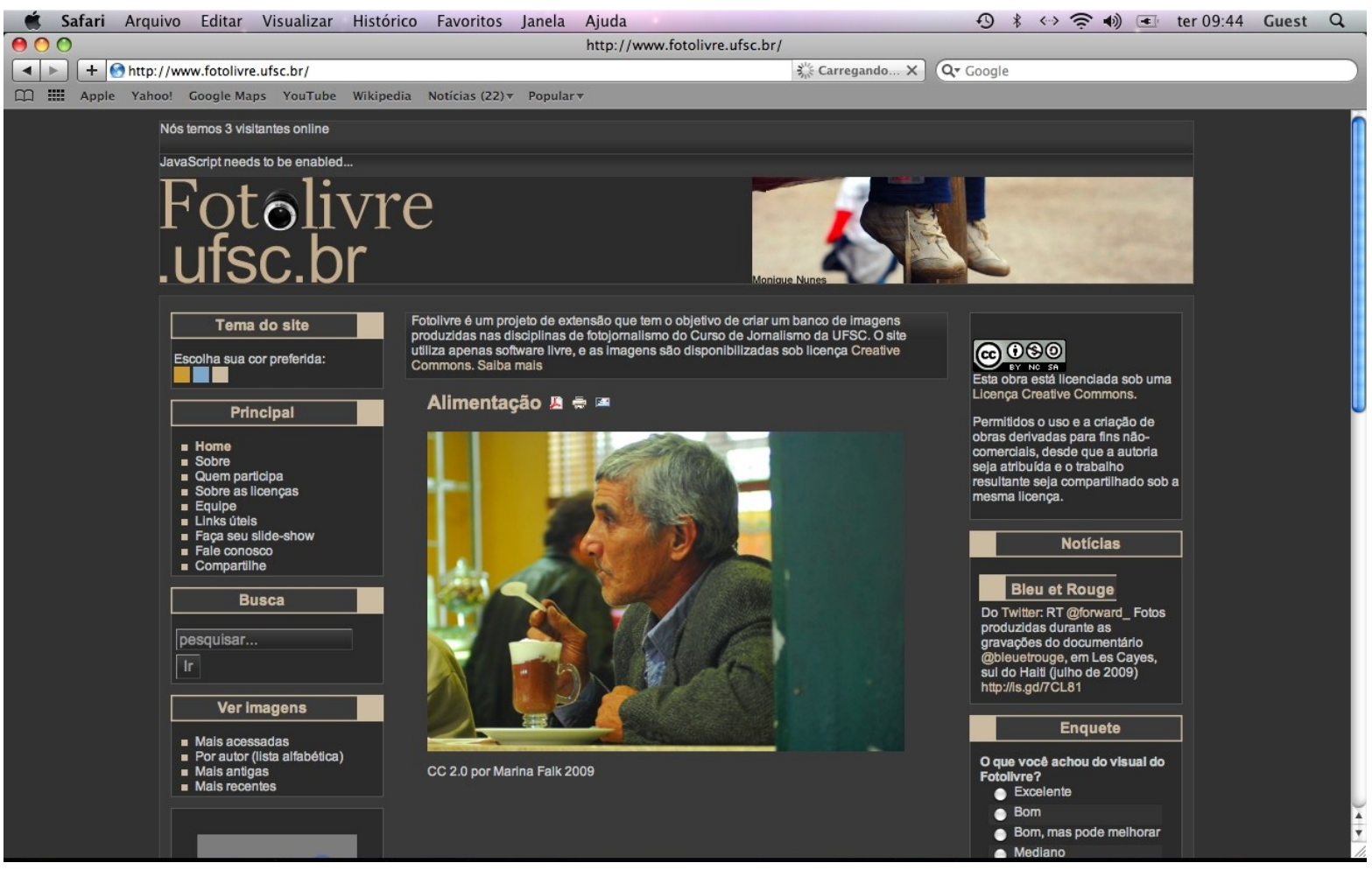

Ilustração 1 - Homepage do site.

Fonte: Fotolivre.ufsc

O lançamento, assim como o estande, foi realizado pela equipe, que esteve presente diariamente na Feira para contato com o público. A terceira etapa compreendeu a alimentação do site e do banco de imagens com a produção dos alunos do segundo semestre de 2009, das disciplinas de Fotojornalismo I, II e III, em dezembro.

\section{RESULTADOS E ANÁLISE}

O impacto do projeto na comunidade foi sentido de duas formas: pelos e-mails recebidos e pelas visitas e comentários no estande da Sepex. No primeiro caso, estudantes, profissionais, pesquisadores e pessoas da comunidade em geral se comunicaram com os 
responsáveis para elogiar, parabenizar a ideia e fazer sugestões. Já durante a feira, muitos visitantes procuraram saber mais detalhes sobre o site, creditando bons frutos pela iniciativa.

Um resultado bastante concreto foi a utilização de uma imagem do site no anúncio feito pela Agência de Comunicação da UFSC para o Dia do Funcionário Público, que foi publicado na imprensa catarinense em 28 de novembro de 2009. Outro resultado do projeto foi a participação e divulgação das iniciativas no XXVII Seminário de Extensão Universitária da Região Sul, SEURS, com apresentação do projeto ao público sulista brasileiro.

Desde seu lançamento, o site figurou entre os primeiros listados pelo buscador Google, e chamou a atenção de entusiastas da fotografia e do software livre. O caráter inovador e transdisciplinar da experiência foi responsável, ainda, por estimular uma nova forma de se pensar a distribuição de conteúdo na Web. O Fotolivre.ufsc está inserido no cenário da cultura da colaboração. Na Web, colaboradores do mundo inteiro fizeram da Wikipedia (em inglês) uma enciclopédia viva com mais de três milhões de verbetes. O banco Wikimedia Commons atingiu recentemente a marca de mais de cinco milhões de arquivos. É evidente que o sistema de proteção de direitos precisa ser revisto para adaptar-se a uma época em que a posse não é mais de uma única empresa ou de algumas poucas, mas de uma comunidade.

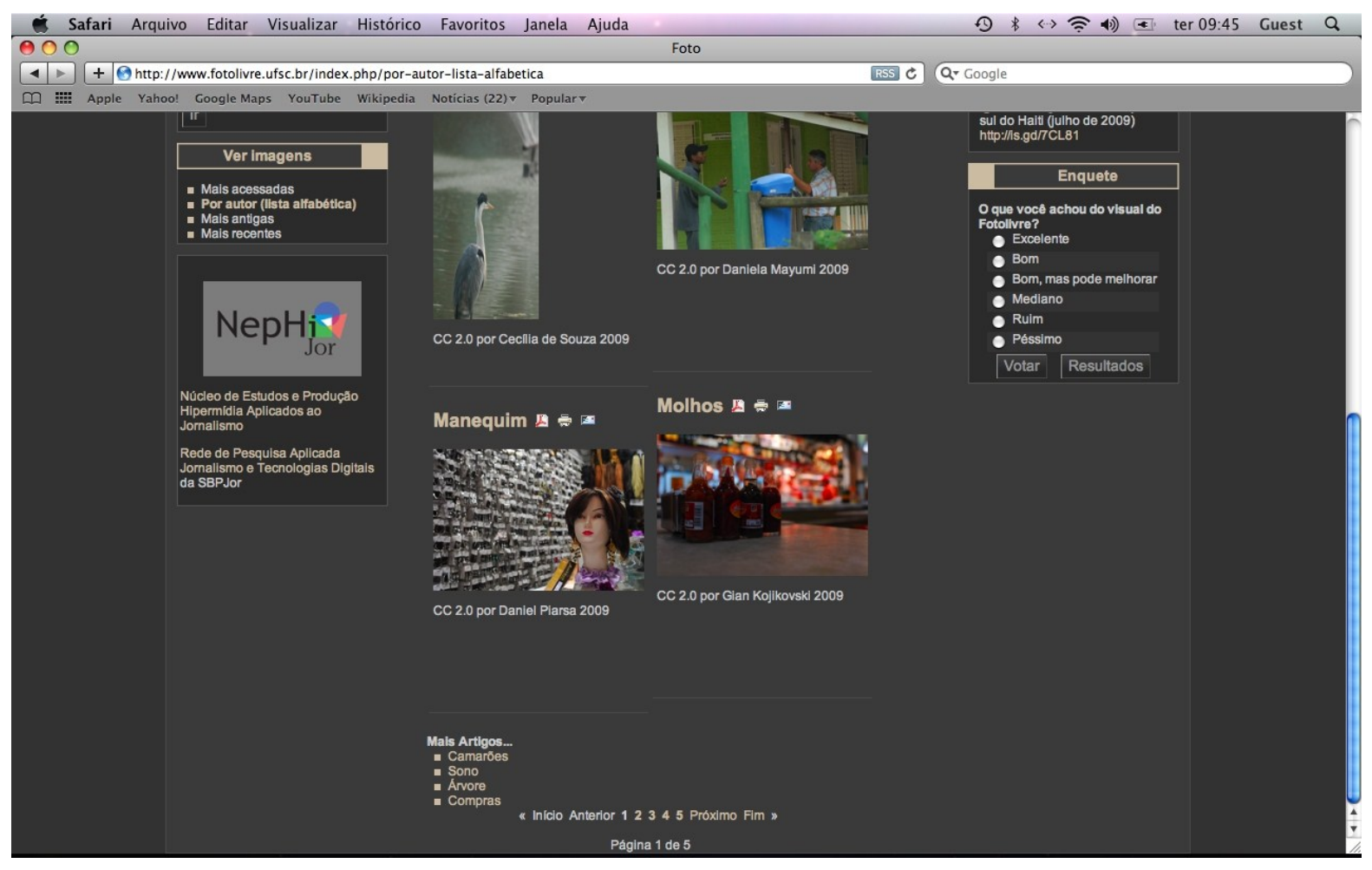

Ilustração 2 - Resultado de pesquisa no site.

Fonte: Fotolivre.ufsc 
A transformação que as NTCI provocam no sistema de produção de conteúdo é gradual, porém irreversível. Descentralizada, não está mais sujeita a decisões de gatekeepers, que decidem o que é publicado e o que não é. O que é interessante, mas não é publicado, logo "vaza" em redes sociais e é rapidamente compartilhado par a par, atingindo a marca de milhares de visualizações. Não existe mais quem represe informação, e se faz necessário navegar com os ventos que encontramos. No caso, adaptar-se a tais transformações.

Quando o assunto é software livre, não há dúvidas de que muitos problemas que as universidades públicas brasileiras têm com equipamento de informática poderiam ser resolvidos se fosse adotado o uso de software livre. Software pago é caro e logo torna-se ultrapassado por novas versões. É necessário que a discussão sobre o uso de software livre continue, ao menos em lugares como as universidades públicas, em que a produção do conhecimento poderia estar mais desvinculada de interesses mercadológicos.

\section{CONSIDERAÇÕES FINAIS}

A ideia de criar um site com banco de imagens produzidas pelos alunos do Curso de Jornalismo da UFSC nasceu como uma forma de abrir um espaço para divulgação de sua produção e proporcionar possibilidades de criação e experimentação de formatos fotojornalísticos nos meios digitais. Dessa forma, o projeto Fotolivre.ufsc proporcionou a experiência de criação de um site e banco de imagens, pelos alunos bolsistas, além de proporcionar, aos alunos das disciplinas de Fotojornalismo, a publicação de sua produção.

Há um interesse cada vez maior na utilização das Novas Tecnologias de Informação e Comunicação não apenas no registro fotográfico, mas na disponibilização do produto fotográfico. Novas ferramentas de criação surgem frequentemente, inclusive aquelas chamadas "livres", ou seja, disponíveis on-line para qualquer usuário, e que não necessitam da compra de licença de uso. O caráter de colaboração, portanto, inerente ao software livre, marcou a ideia principal do projeto, ou seja, utilizar ferramentas livres para a criação e escoamento do material produzido pelos alunos e, ainda, disponibilizar aplicativos para a criação de formatos fotojornalísticos, como slide-shows, através do site. 
A grande receptividade gerada entre o público em geral, assim como na comunidade do software livre, suscitando a discussão sobre a utilização dessas ferramentas na prática cotidiana e profissional foi um dos pontos notáveis do projeto.

Como aspectos a serem melhorados, ressaltam-se a agenda de atualização do site, que depende dos resultados das disciplinas de Fotografia do Curso de Fotojornalismo, o que se dá, geralmente, ao final de cada semestre. A atualização dos conteúdos está contando atualmente com materiais de 2009 e 2010. A possível renovação do projeto, portanto, deverá permitir uma agilidade maior na atualização do banco de imagens.

\section{REFERÊNCIAS}

ALVAREZ MARCOS, José. 'El periodismo ante la tecnologia hipertextual', in: Noci, Javier Dias e Aliaga, Ramon Salavería (orgs.). Manual de Redacción Ciberperiodística.

Barcelona: Ariel, p. 231-258, 2003.

CANAVILHAS, João. Webnotícia: propuesta de modelo periodístico para la WWW.

Universidade de Beira Interior, 2007.

CREATIVE COMMONS. Disponível em: $<\underline{\text { http: } / / w w w . c r e a t i v e c o m m o n s . o r g . b r />~}$. Acesso em: 12 de maio de 2009.

LIMA, Pedro Henrique J. V. Fotolovre.UFSC. In: $27^{\circ}$ Seminário de Extensão Universitária da Região Sul, Universidade Federal de Santa Maria, Rio Grande do Sul, 2009.

MANOVICH, Lev. El lenguage de los nuevos medios de comunicación. Buenos Aires: Paidós, 2006.

McADAMS, Mindy. Flash Journalism. How to create multimedia news packages. Burlington, MA, USA: Focal Press/Elsevier. 2005.

WIKIMEDIA COMMONS. Disponível em:

$<$ http://commons.wikimedia.org/wiki/Main_Page> . Acesso em: 20 de maio de 2009.

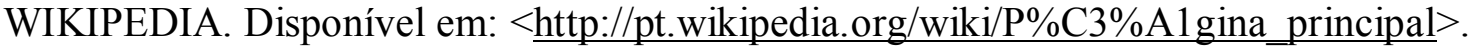
Acesso em: 10 de maio de 2009.

\section{AGRADECIMENTOS}

O projeto Fotolivre.ufsc foi contemplado com o Pró-Bolsa e o Pró-Extensão 2009 da Universidade Federal de Santa Catarina, por isso, um agradecimento especial à Universidade. 
Ele não teria sido possível sem o apoio do Departamento de Extensão, que muito colaborou com as dúvidas e esclarecimentos sobre a atividade.

Os professores Ivan Giacomelli e Cristiane Fontinha, encarregados das disciplinas de Fotografia do Curso de Jornalismo da UFSC prestaram uma inestimável colaboração com o projeto, ao fazerem a pré-seleção das imagens dirigidas ao site, por isso, nossos agradecimentos. Aos alunos das disciplinas de Fotografia dos semestres 2009/01 e 2009/02, pelo entusiasmo e colaboração, também agradecemos.

Apoio fundamental para o projeto foi o do DAE - Departamento de Administração Escolar, que, na pessoa de seu diretor, Dalton Barreto, tornou possível a impressão de material de divulgação, como marcador de livro e banners. 